\title{
A study on relationship between organizational culture and information technology on knowledge sharing
}

\author{
Vahid Ghasemi $^{\mathrm{a}^{*}}$, Hamid Ghasemi ${ }^{\mathrm{b}}$ and Fatemeh Farahani ${ }^{\mathrm{a}}$
}

${ }^{a}$ Department of Cultural Management, Science and Research Branch, Islamic Azad University, Tehran, Iran ${ }^{b}$ Department of Management, Karaj Payam Noor University, Karaj, Iran

C H R O N I C L E

Article history:

Received January 20, 2014

Accepted 30 August 2014

Available online

September 152014

Knowledge sharing

Organizational culture

Trust

Reward system

IT

\section{Introduction}

Knowledge has been a controversial debate in western philosophy for years (Betz, 2001). During the past several years, there has been a growing interest in considering knowledge as an organizational asset. Information sharing (IS) researchers have begun promoting a class of information systems stated as as knowledge management systems (KMS). The primary objective of KMS is to provide some support on creation, transformation, and application of knowledge in all sorts of firms. Effective development and implementation of KMS needs a foundation in various rich literatures. To be credible, KMS research and development have to preserve and construct on the literature, which exists in various but related fields. Alavi and Leidner (2001) presented a comprehensive review and interpretation of knowledge management literatures in various fields with the focus towards determining the important areas for research. They presented a detailed process view of organizational knowledge management with a concentration on the potential role of information technology in this process.

*Corresponding author. Tel:+989123136389

E-mail addresses: Gh vahid1969@yahoo.com (V. Ghasemi)

(C) 2014 Growing Science Ltd. All rights reserved. doi: $10.5267 /$ j.ms 1.2014 .9 .010 
Hicks et al. (2007) investigated the current thoughts on knowledge management (KM). They developed a metaphor to combination of these thoughts in a new way that effectively conveyed various kinds of knowledge and ways of managing it. According to Christensen (2007), Knowledge sharing is the best method for moving away from the obsession with best practices.

\section{The proposed study}

This paper presents an empirical investigation to study the effects of organizational culture and information technology on knowledge sharing (Al Busaidi et al., 2010; Daft, 2006) in national foundation of computer games (NFCG) located in city of Tehran, Iran. The proposed study designs a questionnaire in Likert scale, distributes it among 55 selected people who work for NFCG, which consists of three categories of organizational culture, information technology (Davenport \& Prusak, 1998) and knowledge sharing (Huysman \& Wulf, 2006) and Cronbach alphas are calculated as 0.869, 0.707 and 0.773 , respectively. The results of these values are well above the minimum acceptable level of 0.70 . Therefore, we can confirm the overall questionnaire of the survey. There are two main hypotheses as well as four sub-hypotheses associated with the proposed study of this paper (Fig. 1).

1. First main hypothesis: There is a positive and meaningful relationship between knowledge sharing and organizational culture.

2. Second main hypothesis: There is a positive and meaningful relationship between information technology and knowledge sharing.

There are four sub-hypotheses associated with the proposed study of this paper as follows,

2.1. There is a meaningful and positive relationship between trust and knowledge sharing.

2.2. There is a meaningful and positive relationship between employee communication and knowledge sharing.

2.3. There is a meaningful and positive relationship between reward system and knowledge sharing.

2.4. There is a meaningful and positive relationship between organizational structure and knowledge sharing.

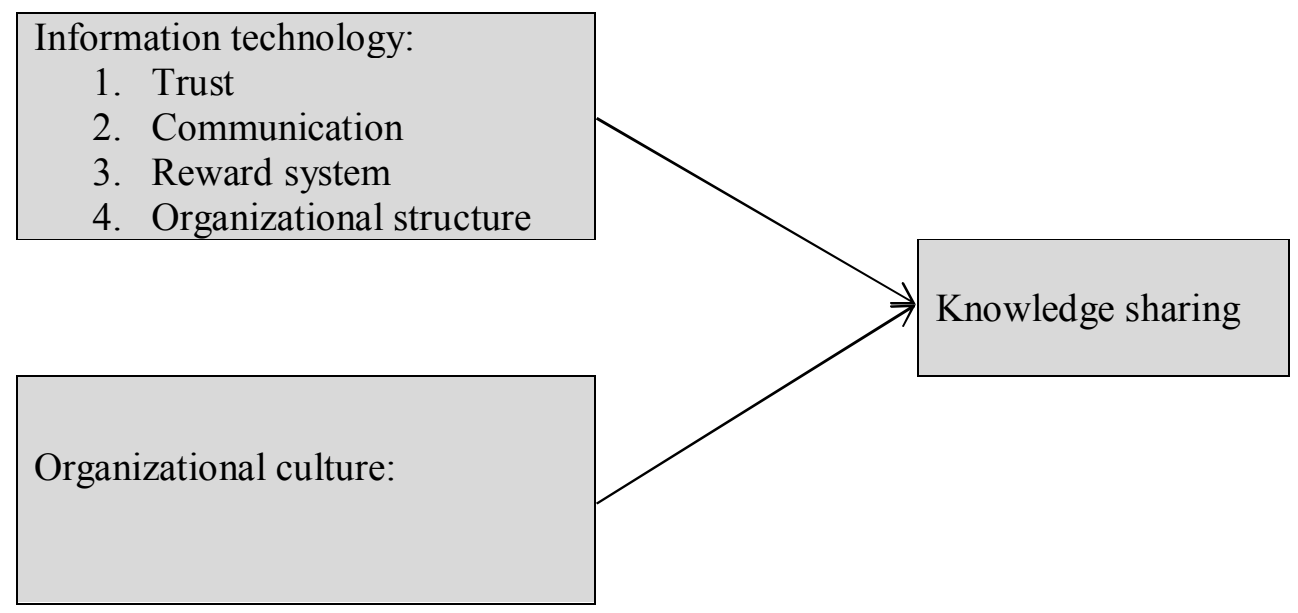

Fig. 1. The proposed study 
Table 1 demonstrates the results of Kolmogrove-Smirnove test to verify whether the gathered information.

\section{Table 1}

The results of Kolmogrove-Smirnove

\begin{tabular}{lccccc}
\hline Variable & Number & Mean & Standard deviation & Z-value & P-value \\
\hline Organizational culture & 51 & 70.16 & 10.34 & 0.474 & 0.978 \\
Information technology & 52 & 33.53 & 5.04 & 0.585 & 0.884 \\
Knowledge sharing & 53 & 32.02 & 5.09 & 0.90 & 0.393 \\
\hline
\end{tabular}

As we can observe from the results of Table 1, all components of the survey are normally distributed.

\section{The results}

In this section, we present details of our findings on testing various hypotheses of the survey.

\subsection{The first hypothesis: The relationship between organizational culture and knowledge sharing}

The first hypothesis of the survey investigates the relationship between organizational culture and knowledge sharing. Table 2 demonstrates the results of Analysis of Variance (ANOVA) test for testing the first hypothesis of the survey.

Table 2

The results of ANOVA test for testing the first hypothesis of the survey

\begin{tabular}{lccccc}
\hline & Sum of Squares & df & Mean of Squares & F-value & P-value \\
\hline Regression & 108.725 & 1 & 108.725 & & \\
Residual & 1106.687 & 49 & 22.585 & 4.814 & 0.033 \\
\hline Total & 1215.412 & 50 & & & \\
\hline
\end{tabular}

As we can observe from the results of Table 2, there is a meaningful relationship between organizational culture and knowledge sharing when the level of significance is five percent. Therefore, the first hypothesis of the survey has been confirmed.

\subsection{The second hypothesis: The relationship between information technology and knowledge sharing}

The second hypothesis of the survey studies the relationship between information technology and knowledge sharing. Table 3 shows the results of ANOVA test for testing the first hypothesis of the survey.

Table 3

The results of ANOVA test for testing the second hypothesis of the survey

\begin{tabular}{lccccc}
\hline & Sum of Squares & df & Mean of Squares & F-value & P-value \\
\hline Regression & 65.363 & 1 & 65.363 & & \\
Residual & 1256.369 & 49 & 25.127 & 2.601 & 0.113 \\
\hline Total & 1321.692 & 50 & & & \\
\hline
\end{tabular}

As we can see from the results of Table 3, there is not any meaningful relationship between information technology and knowledge sharing when the level of significance is five percent. Therefore, the second main hypothesis of the survey has not been confirmed. 


\subsubsection{The first sub-hypothesis: The relationship between trust and knowledge sharing}

The first sub-hypothesis of the survey tries to find out the relationship between trust and knowledge sharing. Table 4 presents the results of ANOVA test for testing the first sub-hypothesis of the survey.

Table 4

The results of ANOVA test for testing the first sub-hypothesis of the survey

\begin{tabular}{lccccc}
\hline & Sum of Squares & df & Mean of Squares & F-value & P-value \\
\hline Regression & 13.622 & 1 & 13.622 & & \\
Residual & 1324.301 & 49 & 26.486 & 0.514 & 0.477 \\
\hline Total & 1337.923 & 50 & & & \\
\hline
\end{tabular}

As we can see from the results of Table 4, there is not any meaningful relationship between employee trust and knowledge sharing when the level of significance is five percent. Therefore, the first subhypothesis of the survey has not been confirmed.

\subsubsection{The second sub-hypothesis: The relationship between communication and knowledge sharing}

The second sub-hypothesis of the survey attempts to determine the relationship between employee communication and knowledge sharing. Table 5 shows the results of ANOVA test for testing the second sub-hypothesis of the survey.

Table 5

The results of ANOVA test for testing the second sub-hypothesis of the survey

\begin{tabular}{lccccc}
\hline & Sum of Squares & df & Mean of Squares & F-value & P-value \\
\hline Regression & 64.493 & 1 & 64.493 & & \\
Residual & 1282.488 & 49 & 25.147 & 2.565 & 0.115 \\
\hline Total & 1346.981 & 50 & & & \\
\hline
\end{tabular}

As we can see from the results of Table 5, there is not any meaningful relationship between employee communication and knowledge sharing when the level of significance is five percent. Therefore, the second sub- hypothesis of the survey has not been confirmed.

\subsubsection{The third sub-hypothesis: The relationship between reward system and knowledge sharing}

The third sub-hypothesis of the survey investigates the relationship between reward system and knowledge sharing. Table 6 presents the results of ANOVA test for testing the third sub-hypothesis of the survey.

\section{Table 6}

The results of ANOVA test for testing the third sub-hypothesis of the survey

\begin{tabular}{lccccc}
\hline & Sum of Squares & df & Mean of Squares & F-value & P-value \\
\hline Regression & 107.043 & 1 & 107.043 & & \\
Residual & 1116.187 & 49 & 22.324 & 4.795 & 0.033 \\
\hline Total & 1221.231 & 50 & & & \\
\hline
\end{tabular}

As we can observe from the results of Table 6, there is a meaningful relationship between reward system and knowledge sharing when the level of significance is five percent. Therefore, the third subhypothesis of the survey has been confirmed. 
3.2.4 The fourth sub-hypothesis: The relationship between organizational structure and knowledge sharing

The fourth sub-hypothesis of the survey investigates the relationship between organizational structure and knowledge sharing. Table 7 shows the results of ANOVA test for testing the fourth subhypothesis of the survey.

Table 7

The results of ANOVA test for testing the fourth sub-hypothesis of the survey

\begin{tabular}{lccccc}
\hline & Sum of Squares & df & Mean of Squares & F-value & P-value \\
\hline Regression & 224.287 & 1 & 224.287 & & \\
Residual & 1122.694 & 49 & 22.014 & 10.189 & 0.002 \\
\hline Total & 1364.981 & 50 & & & \\
\hline
\end{tabular}

As we can observe from the results of Table 7, there is a meaningful relationship between organizational structure and knowledge sharing when the level of significance is five percent. Therefore, the fourth sub-hypothesis of the survey has been confirmed.

\section{Conclusion}

We have presented an empirical investigation to study the impact of organizational culture and information technology on knowledge sharing in national foundation of computer games (NFCG) located in city of Tehran, Iran. Using ANOVA test, the study has determined a positive and meaningful relationship between organizational cultures and knowledge sharing. However, the study has not determined any positive and meaningful relationship between information technology and knowledge sharing. Furthermore, while the results of the study have not indicated any meaningful relationships between trust, employee communication on one side and knowledge sharing on the other side, there were positive and meaningful relationships between reward system and organizational structure on one side and knowledge sharing on the other side. Based on the results of the survey, we can conclude that reward may increase the employees' motivation to share knowledge and help organization grow faster.

The findings of this survey are somewhat consistent with other studies. Jiacheng et al. (2010), for instance, explored individual cognitive mechanisms of knowledge-sharing (KS) motivation and intends to incorporate more effective measures to judge and effect individual inclinations toward KS in a cross-cultural context in Chinese community. They reported that Chinese had more tendencies to conform to teams' opinions and tend to favor KS as a tool of reaching harmonious relationships, while Americans engaged in KS because self-worth was considered as the manifestation of their individual determinations. The result of our study is not consistent with the results of other studies in terms of trust (Nonaka \& Takeuchi, 1995; Issa \& Haddad, 2008; Wang \& Noe, 2010). According to Lin (2008), for instance, trust and commitment among units, which are important for facilitating knowledge sharing among units, and creative and supporting characteristics of organizational culture could be beneficial for the implementation of knowledge sharing activities and this is not what this study has found about it.

\section{Acknowledgement}

The authors would like to thank the anonymous referees for constructive comments on earlier version of this paper. We are also delighted for the cooperation we received from the employees of national foundation of computer games (NFCG). 


\section{References}

Alavi, M., \& Leidner, D. E. (2001). Review: Knowledge management and knowledge management systems: Conceptual foundations and research issues. MIS quarterly, 25(1), 107-136.

Betz, F. (2001). Executive strategy: Strategic management and information technology. John Wiley \& Sons.

Al Busaidi, K. A., Olfman, L., Ryan, T., \& Leroy, G. (2010). Sharing knowledge to knowledge management system: Examining the motivator and the benefits in a Omani organization. Journal of Organizational KM, 928-935.

Christensen, P. H. (2007). Knowledge sharing: moving away from the obsession with best practices. Journal of knowledge management, 11(1), 36-47.

Daft, R. (2006). Organization theory and design. Cengage learning.

Davenport, T. H., \& Prusak, L. (1998). Working knowledge: How organizations manage what they know. Harvard Business Press.

Hicks, R. C., Dattero, R., \& Galup, S. D. (2007). A metaphor for knowledge management: explicit islands in a tacit sea. Journal of Knowledge Management,11(1), 5-16.

Huysman, M., \& Wulf, V. (2006). IT to support knowledge sharing in communities, towards a social capital analysis. Journal of Information Technology, 21(1), 40-51.

Issa, R. R., \& Haddad, J. (2008). Perceptions of the impacts of organizational culture and information technology on knowledge sharing in construction. Construction innovation: Information, process, management, 8(3), 182-201.

Jiacheng, W., Lu, L., \& Francesco, C. A. (2010). A cognitive model of intra-organizational knowledge-sharing motivations in the view of cross-culture. International Journal of Information Management, 30(3), 220-230.

Lin, W. B. (2008). The effect of knowledge sharing model. Expert Systems with Applications, 34(2), $1508-1521$.

Nonaka, I., \& Takeuchi, H. (1995). The knowledge-creating company: How Japanese companies create the dynamics of innovation. Oxford university press.

Wang, S., \& Noe, R. A. (2010). Knowledge sharing: A review and directions for future research. Human Resource Management Review, 20(2), 115-131. 